\title{
EUTOMIA
}

Revista de Literatura e Linguística

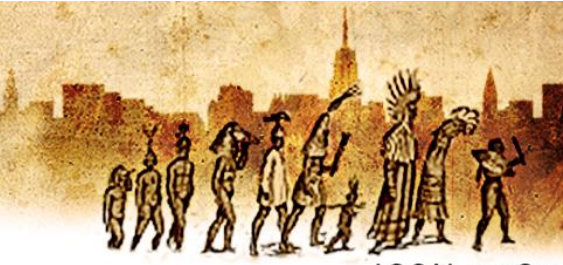

ISSN $1982-6850$

\section{Linha: o desfiar poético de Edgar Braga}

Omar Salomão - PUC-Rio

Resumo: Sobre os procedimentos grafo-poéticos da poesia visual de Edgard Braga. Capítulo da dissertação de mestrado: Gosto de caminhar nas ruínas ou Fragmentário: onde mancha e linha se confundem.

Abstract: On the visual-poetic procedures of Edgard Braga's visual poetry. Chapter of the master's dissertation: Like to walk among ruins or Fragmentary: where stain and line are confused.

Edgard Braga era um nome desconhecido pra mim. Até deixarem, em 2013, na portaria do meu prédio, um envelope pardo com o cartão de uma procuradora da justiça de São Paulo grampeado.

Beatriz Helena Ramos Amaral, estava escrito no cartão, que era atravessado por um risco azul de caneta. Risco cruzando o pequeno papel, cortando o sobrenome e o cargo. Risco: código protocolar como uma forma de, supostamente, se quebrar a formalidade. Me chame pelo meu nome apenas, pretende informar. Informar com um 
risco. Um gesto curto e rápido. Impreciso - não tem a necessidade de atingir tudo, nem de tornar ilegível ou apagar, ao contrário, a leitura se mantém nítida. É uma marca clara da presença, de inserir o corpo no cartão de visita, diminuir um tanto da frieza gráfica. Um movimento formal que rasura para trazer pessoalidade ao protocolo.

Dentro do envelope: A transmutação metalinguística na poética de Edgard Braga, livro de capa branca publicado por Ateliê Editoral. A autora era a própria procuradora, também poeta ${ }^{1}$. Recente, do mesmo ano de 2013, o livro trazia a dissertação de Mestrado em Literatura e Crítica Literária pela PUC-SP, defendida por Beatriz em 2005. Dentro, encontrei uma dedicatória: "Para Omar Salomão, que está neste livro pág. 98 - na viagem pelo transmutante universo poético de Edgard Braga, o abraço amigo e metapoét ico da Beatriz." No fundo do cartão de visitas, depois vi, tinha outra saudação e uma referência ao meu pai (que Beatriz havia conhecido em 1996, em um evento de poesia), mas meu primeiro movimento foi abrir o livro na página 98.

Era a última página do capítulo 3: "Nesta linhagem estética de invenção, de escritura marcada pela incorporação de elementos visuais que introduzem o gesto criador no próprio texto poético, inserem-se trabalhos e projetos de vários autores contemporâneos, entre os quais se destaca a obra Impreciso, de Omar Salomão (Dantes Ed., Rio de Janeiro, 2011)." Fim de capítulo. Ergui os olhos para o parágrafo anterior. Arnaldo Antunes era quem desenhava a linhagem estét ica ao reconhecer, em seu artigo Derme/Verme ${ }^{2}$, Edgard Braga como o primeiro poeta brasileiro a trabalhar com manuscritura, sobretudo em um contexto de influência da poesia concreta com os experimentos sendo realizados intensamente no campo gráfico da tipologia (ANTUNES apud. AMARAL, 2013, p.98).

Orgulhoso e feliz - primeira vez que me fazem referência em um livro - circundei o trecho com um brilhante pillot vermelho e folheei erraticamente as páginas

\footnotetext{
1 O pacote trazia mais uma surpresa, o intrigante livro de poemas, Luas de Júpiter (Anome Livros, 2007), da Beatriz Amaral.

2 "Publicado na Folha de S. Paulo, em 2 de janeiro de 1991 e, posteriormente, em seu livro 40 Escritos", escreve Beatriz Helena Ramos AMARAL (2013, p.98).
} 
restantes. A transmutação. A transmutação metalinguística na poética de Edgard Braga...

O dicionário não me levou para muitos lugares: Transmutar v. 1 transportar, transferir, mudar, converter em, tornar diferente. Transmutação s.f. 1 ato ou efeito de transmutar(-se) (HOUAISS. 2001). Sigo pelo livro. O primeiro dado a me chamar atenção era um acaso. O alagoano Braga nasce no mesmo ano (1897) da publicação de Um lance de dados do Mallarmé - poema que escancara as portas da percepção da poesia para o espaço, o tempo, a página, o leitor, sobre a própria poesia e que será essencial para a liberdade poética de Braga. Apesar de escrever e publicar desde os anos 1920, é apenas na virada dos anos 1950 para 1960, a partir da aproximação com a estética concretista - movimento que descende do poema de Mallarmé ao aprofundar investigações acerca de estruturas espaciais e formas não versificadas nos poemas, dentre outros objetivos - que ganha destaque. O livro Soma, publicado em 1963 (São Paulo, ed. Invenção) é "o primeiro a receber da crítica aplauso irrestrito e a inserir seu autor definitivamente, entre os principais representantes da poesia concreta brasileira" (AMARAL, 2013. p. 71). A sólida antologia da obra de Braga, Desbragada (Ed. Max Limonad, 1984), organizada por Régis Bonvicino, não incluiria qualquer poema de livros anteriores ao Soma.

Esse ápice de criação poética (transmutação na escrita e no olhar) ocorrido após os seus 60 anos, se deve em parte a uma estreita relação com os principais expoentes concretos brasileiros: Augusto de Campos, Décio Pignatari e Haroldo de Campos. Os três, além de escreverem textos sobre o trabalho de Braga, organizaram três livros: Soma, que ainda recebeu design de Pignatari; Algo (São Paulo, ed. Invenção, 1971) organizado por Décio e Augusto; Tatuagens (São Paulo, ed. Invenção, 1976), que teve os poemas selecionados por Augusto e Régis Bonvicino, além de um projeto gráfico primoroso em pranchas criado por Julio Plaza. A estreita proximidade fez com que Edgar Braga fosse classificado como um poeta concret ista. Gosto do comentário que Régis Bonvicino faz sobre essa leitura: "Não considero concretista o trabalho de 
Braga, sobretudo Algo e Tatuagens. Os poemas concretos, dos outros, da década de 50 e 6o, são cuidadosamente pensados, feitos à base de um 'racionalismo sensível'; já os de Braga são, digamos, casuais e inspirados: o que nele sente, pensa depois" (BONVICINO. Biografia de um livro. In.: BRAGA, 1984, página sem número). Não pretendo entrar nas características nem no racionalismo do concretismo. O ponto chave da observação de Bonvicino é o sente. Sent ir. É a necessidade do corpo que gera a transgressão de Braga de buscar o giro do punho, a irregularidade da tinta (e afinal, porque o corpo teria que ser recalcado do poema?). Grafo-tátil será a forma que Haroldo de Campos vai encontrar para chamar as criações de Edgar Braga.

Bonvicino desdobra um pouco além, ao enxergar um amadorismo no traço do desenho de Braga como opção pela "estética do provisório", da precariedade: "precariedade aqui entendida em seu duplo sentido: de coisa pouco durável, mas também rara e difícil". Observação certeira, ao que parece, é quando Braga se suja e deixa de dar importância à importância (ou ao verso, ao fazer poético, ao lugar de pedestal da escrita) é que seu trabalho encontra a falha, se torna errático, imprevisível. Até mesmo repet itivo. Volto ao toque e ao lance ao encontrar esse poema do livro Soma:

dedos-dados dados em lanço de pontos pretos

um lenço um cachimbo

em preto-branco espaço

remate do poema branco.

Dedos-dados - os dedos 3 são os próprios dados a tatear o acaso, deixando rastros pretos, deixando o espaço preto-branco. Limite do vazio, o branco que é poema. Os pontos pretos, lances. Alguns anos depois, Braga retoma o jogo dedos-dados em um poema visual ${ }^{4}$ (Ver anexo). O manuscrito preto e branco, traçado com linhas grossas, é composto dentro de um retângulo recortado por linhas diagonais, remetendo tanto a um tabuleiro, quanto ao design de poemas concretos, feito os do livro Tango with Cows (1914) do futurista russo Vasily Kamensky, que fracionou o poema

3 "O vocábulo dedos aparece com muita frequência na poesia de Braga, (....) e este fato ressalta a marca do poeta, a presença física da mão, do gesto de manuscritura. Os dedos tatuam vários de seus poemas." AMARAL, 2013, p. 153

$4 \quad$ Dedos dados, feito em 1966 e publicado no livro Tatuagem (Edições Invenção, 1976). 
espacialmente através de elegantes finos fios diagonais. Braga lança pelo tabuleiro as palavras: DEDOS, DADOS e derivações fônicas - DE, DARDOS, DÉDALO (Dédalo, na mitologia grega, é um inventor e arquiteto, criador do labirinto construído para aprisionar o Minotauro).

Os dedos são agentes do eu do poeta. Os dados representam o aleatório, as infinitas possibilidades da construção poética. Dardos, por sua vez, apresentando o mesmo significado de lanças, sugerem o movimento de construção do poema, a orientação deste movimento, que se desdobra pelas várias e múltiplas direções em que se desenham as palavras. Poemas - como dardos - se lançam, como no acaso mallarmaico. ( AMARAL, 2013, p.155)

Dédalo criador do labirinto dos labirintos. Seria Mallarmé, Dédalo? Sem dúvida, mas Dédalo poderia ser também outro. Dédalo, pai de Ícaro, inventor de asas, asas de cera para voar mas não perder de vista a terra. Asas - poeta que transforma palavras em dardos - lances e lanças - a perfurar o mar, o muro, as páginas. E o que imaginar ao saber que o futurista Kamensky foi um dos primeiros russos a pilotar um avião? E o que saber ao imaginar o poeta furando o ar?

Constant inopla. Poema de Vasily Kamensky fatiado por fios feito planos de voo de cartas aéreas. Palavras empilhadas de um olhar pela capital da Turquia (Constant inopla, antiga Bizâncio, atual Istambul). É um poema sem começo nem fim. Braga mimetiza a estrutura de forma amadora. O traço é grosso e levemente instável. As palavras giram, como se além de não ter começo nem fim, não houvesse lado. Pode-se ler girando. Brincando. Jogando. Palavras-dardo giram no ar. Ícaro se encanta pelo alto, quer subir. Cai. 
Decifração enigmática. Braga encarna o jogo, abre o tabuleiro (página) e lança algumas determinadas peças: limitar as palavras, usar um número mínimo de palavras. Espelhar. Inverter palavras na frase. Quase infant il: 5

$\begin{array}{lc}\text { um pobre } & \text { joga } \\ \text { um } \\ \text { jogo } & \text { pobre } \\ \text { joga um } & \text { jogo } \\ \text { um pobre } & \text { joga } \\ \text { joga joga } & \text { joga } \\ \text { um pobre } & \text { joga } \\ \text { jogo pobre } \\ \text { um } \\ \text { joga }\end{array}$

As palavras brincam, driblam, espacializadas no papel. Um jogo de poucas palavras. Pobre. Mínimo. Se espalha pelo espaço e joga. Só disso foi preciso para se jogar: algum espaço e poucas palavras. Da essência. É o desdobrar do poema, publicado no mesmo livro (Soma). Poema repetido. A palavra usada, de novo e outra vez mais. Volto ao "poema/ poema/ poema/ poema/ poema/ poema", até se decifrar sua maquinária, seu funcionamento, seu mínimo - "pó/ e mó". A pedra de moer e afiar: "Mó s.f. 1 pedra grande dura, cicular, de altura pequena, com que se trituram os grãos nos moinhos. (...) 2 pedra pequena circular com que se amolam facas, tesouras e outros instrumentos cortantes." 6 Os restos do corpo, o chão, o farelo da pedra: "Pó s.m. 1 partículas tenuíssimas de terra seca que pairam no ar e se depositam no solo; poeira 2 qualquer substância sólida e seca reduzida a partículas tenuíssimas." O que tudo isso quer dizer?

\section{IV}

Ponto de disparo:

5 Poema de Edgard BRAGA (1984) publicado originalmente no livro SOMA.
6 Trechos das definições de Mó e Pó. Dicionário HOUAISS. 2001.

Eutomia, Recife, 22(1): 253-272, Dez. 2018 
(...) foi fundamental a descoberta do que era uma coisa óbvia para certas culturas - a cultura árabe, a chinesa, a japonesa - onde evidentemente o poeta era também por natureza aquele que trabalhava com a dimensão gráfica, era um pintor gráfico, era um homem que a qualidade visual do ideograma chinês, do caligrama de um calígrafo árabe, interferia diretamente em seu poema. $O$ poeta era também um calígrafo por definição. São culturas onde não havia essa cisão. [Forma e conteúdo.] (...) O relegar do elemento visual para uma mise-en-page [o layout], que não pertencia ao poeta, mas a alguém que nada tinha a ver com seu trabalho (CAMPOS, 1969, p.66).

A caligrafia e a síntese do ideograma seriam uns dos caminhos de invenção investigados pelas vanguardas históricas no campo da poesia, com destaque para os caligramas, muitos manuscritos, de Guillaume Appolinare, que, sintetiza o pesquisador Philadelpho Menezes, "buscou recuperar a tradição visual dos carmina figurata $^{7}$ medievais, já numa perspectiva de inserção da escritura ideogrâmica do oriente na poesia ocidental" (MENEZES, 1995). Uma experiência de soma do verso livre (não apenas das estruturas de métrica e rima, mas também da própria hierarquia da linha no espaço) com a forma que o poema representava.

Talvez esse trecho, retirado do Plano-piloto para Poesia Concreta8, demonstre parte do interesse vanguardista: "ideograma: apelo à comunicação não-verbal, o poema concreto comunicação não verbal. o poema concreto comunica a sua própria estrutura: estrutura-conteúdo. o poema concreto é um objeto em e por si mesmo, não por um intérprete de objetos exteriores e/ou sensações mais ou menos subjet ivas." Ou seja, foco no poema enquanto síntese completa: forma, imagem, texto, som. "a poesia concreta visa ao mínimo múlt iplo comum da linguagem". Fecho o parêntesis.

\section{V}

$7 \quad$ Carmina figurata é um poema medieval que tinha determinado formato ou padrão (por exemplo: uma taça de vinho ou um triângulo). Fonte: https://en.wikipedia.org/wiki/Carmen figuratum. Visitado dia 05/02/2018. $8 \quad$ Escrito por Augusto de Campos, Décio Pignatari e Haroldo de Campos foi publicado em 1958 na revista Noigandres 4.

Eutomia, Recife, 22(1): 253-272, Dez. 2018 
Quer dizer, para onde isso tudo leva? Resumindo: "Creio que, para Braga, a Poesia Concreta serviu como droga libertadora, que o encorajou a abandonar o passado e o verso tradicional na busca de um universo novo de formas interinas e precárias." ${ }^{\text {, }}$ escreve Régis Bonvicino. Essa relação libertação - que desarma a poesia de Braga e a solta no gosto pelo jogo, pela brincadeira, pelo amador - e síntese (mínimo) vai romper no livro seguinte, Algo de 1971 . O pó e a mó na prática. As páginas abrem espelhadas. O lado direito em negativo branco e preto do lado esquerdo (preto e branco). Um emaranhado de $A L G O$, algumas vezes escrito. Letras embaralhadas, ligadas, feito uma trama. E essa trama se desfaz, raspada da página, moída. Em nas páginas seguintes vemos vestígios, rastros. Restos de algo, de tinta. Erosões. Como se algo (uma pedra?) houvesse raspado a superfície - revelando a página branca do papel abaixo, soprado o pó (poema?) que saiu da superfície. O que há imediatamente atrás do poema. Abaixo da tinta. Páginas raspadas, revelando entre as sobras, palavras, as letras pequenas, por vezes ilegíveis, sobrevivendo por trás, sob as sombras do pó - sóis, silêncio, nascimento, lírios \& rios. "As palavras apenas afloram como pegadas de significado", escreve Augusto de Campos sobre Algo $^{10}$. Oito páginas (e seus espelhos) de tinta e resto para no fim, chegar no início do trajeto que algo traz, e do pó e mó, desencavar as letras e voltar a um enorme P O E M A.

\section{VI}

Edgard Braga era um nome desconhecido pra mim¹1. Só após receber, na porta de casa, a "intimação", abri meus olhos para esse voo livre, ou como escreve em um poema, cruzando em diagonal a página com o pincel, um longo UIVÔO (saudades desse acento circunflexo) de repetidas letras, subindo aos céus. Um tempo depois, estava eu frente a biblioteca do meu pai, procurando algo ou outro de Braga. Encontrei Tatuagens, o belíssimo conjunto lançado em 1976. UIVÔO vem de lá. As

9 BONVICINO. Biografia de um livro. In.: BRAGA (1984).

$10 \quad$ CAMPOS, A. Algo sobre Algo.In.: BRAGA (1984). Página sem número.

11 O que, infelizmente, não é propriamente difícil. O último livro com suas obras, Desbragada, foi publicado quando eu tinha um ano de idade, e foi o primeiro a sair por uma editora, na época, de maior circulação, a Max Limonad (hoje, curiosamente, voltada para impressões por encomenda em pequenas tiragens). Não consigo evitar de copiar aqui uma frase de Mallarmé (citado por KRISTEVA, 1972. p. 264): "os contemporâneos não sabem ler". 
pranchas soltas que permitem ler/ver os poemas individualmente e sem ordem fixa ${ }^{12}$. A capa que se dobra feito um origami sobre as folhas para guardá-las, protegê-las. São poemas com rastros de vida. Uma página marcada com carimbos LIMITE DO, OLHO, EU, POEMA. Não há limite, linha. O olho, o eu e o poema se confundem dentro da nuvem de palavras carimbadas. Algumas mais nítidas (com mais tinta e força), outras mais fracas. Por vezes o limite borra o eu. O poema mancha o olho. A silhueta evoca outros múltiplos. Como se a mancha despertasse outros outros. Como escreveu Augusto de Campos: "o que espanta em Edgard Braga é a liberdade total da criação." ${ }^{13}$ A linha do limite é atravessada, ou, sendo mais preciso, é atropelada por outros: palavras falhadas, carimbadas por mãos apressadas, ansiosas por mais olho, mais eu, mais poema para apagar (ou ao menos confundir) os limites.

A "percepção entre o legível e o ilegível e o surpreender a irrupção da palavra no nascedouro"14, escreve Julio Bressane. "É difícil em Braga saber onde termina o texto e começa o traço. A voz traço de difícil demarcação de fronteira, pois trata-se de um dos mestres do trocadilho entre a letra e o traço, de (sem) limite do verbal e do nãoverbal".

\section{VII}

Um pequeno círculo centralizado no final da página. Duas linhas diagonais saem desse círculo para o meio da página, criando um vértice ou a letra $V$. Da ponta da linha da esquerda até a ponta da linha direita, palavras. Muitas. Abrem em leque um arco feito uma Bougainville. Palavras enfileiradas, encaixadas rentes feito os arcos romanos: blocos de pedra sustentados pelas forças de compressão e pelo atrito. Uma palavra

\footnotetext{
12 Algo já era um livro construído com os poemas folhas soltas como explica Carlos Ávila: "envelope com pranchas soltas, onde seus poemas visuais são impressos em positivo/negativo, trabalhados originalmente em nanquim com estilete e letra-set." (Carlos Ávila. Edgard Braga: 85 anos. In.: BRAGA. 1984).

13 Augusto de Campos. Algo sobre Algo.In.: BRAGA (1984). página sem número

14 Julio Bressane. Edgard Braga: o voo inaugural.In.: BRAGA (1984). página sem número
}

Eutomia, Recife, 22(1): 253-272, Dez. 2018 
desviando seu peso sobre a outra. Muitas palavras. Na verdade, poucas palavras escritas muitas vezes. Indo e voltando (escritas ao contrário, espelhada).Algo como: SER VER VER SER VER VER VER VER VER VER VER VER SER SER SER VER VER VER SER SER SER SER SER SER SER SER SER VER VER VER VERBO VERBO VERBO VERBO VERBO VERBO VERBO VERBO VERBO VERBO VERBO VER... Novamente o olho (VER), o eu (SER) e o poema (VERBO) e o rompimento. Flutuar. Um dos blocos de pedra se desprende. Entre SER e VER surge CRIAR / CRIA AR. As palavrar passam a flutuar. Soltas. SER. VER. CRIAR. VERBO. Até descer em direção ao centro do vértice, ao pequeno círculo centralizado no final da páginal, Um firme e solitário SER. ${ }^{15}$

Letras e linhas. Letras e falhas. Letras e riscos. Letras e manchas. $A, E, I, O, U$. $O$ movimento concreto permitiu que Braga enxergasse um fim de caminho com um muro. Aquele limite tantas vezes imperceptivel, do vidro do aquário, que redireciona nosso caminho e assim sentimos como se caminhássemos em frente, que a rua é sem saída e o natural é retornar. Braga subiu o muro.

\section{VIII}

Caminhou torto, se equilibrando por cima do muro - e aqui sem tecer relações com a surrada expressão, pois só o fato de subir já o colocou em outro lugar. Sem afiliações, nem clubes que o aceitem como sócio. O obstreta Braga, que fez o parto das filhas de Oswald de Andrade, subiu com as mãos o muro, vendo o que ninguém viu. Sem dar importância a tanta coisa (as regras, os versos, as rimas), sentou-se ali feito criança, e escavou, entre pedra e pó, palavras no limite entre ver e ser, com o gesto da mão e a imensidão da página.

Bressane, ao se referir a Braga, cita uma passagem do conto de Edgar Allan Poe, The power of words (1850), sobre o poder físico das palavras, que termina: "Não é cada palavra um impulso sobre o ar?"16

15 Poema visual de Edgard Braga: SER VER, publicado em Tatuagens.
16 BRESSANE. Edgard Braga: o voo inaugural. In.: BRAGA (1984).

Eutomia, Recife, 22(1): 253-272, Dez. 2018 


\section{IX}

Edgar Allan Poe: "E cabem também aqui algumas palavras sobre versificação. Meu primeiro objetivo (como de costume) foi a originalidade. Para mim, o modo como este fator tem sido negligenciado em versificação é uma das coisas mais inexplicáveis do mundo. Mesmo reconhecendo que existe pouca possibilidade de variedade no ritmo, é evidente que as variações possiveis em métrica e estrofes são absolutamente infinitas e, no entanto, durante séculos, ninguém jamais fez ou julgou fazer algo original em matéria de versos. Acontece que a originalidade (exceto em mentes de vigor incomum) não é de forma alguma uma questão, como alguns supõem, de impulso ou intuição. Em geral, para ser alcançada, deve ser buscada com afinco e, embora seja um mérito positivo da mais alta categoria, exige em sua obtenção menor invenção do que negação (POE, 2017, p. 349).

Originalidade exige mais negação do que invenção, traça Poe sobre seu ofício (após lixar e raspar e limpar seu poema) no texto. Decidir, selecionar, escolher, cortar. Filosofia da composição - texto escrito em 1846. Poe descreve um processo calculista e rigoroso de como teria construído o poema $O$ corvo, publicado no ano anterior, e que Ihe deu grande fama nos EUA e na Europa. Uma arquitetura depurada de trás para diante, definindo os sentimentos que desejava causar e escrevendo primeiro a estrofe final do poema. É interessante a criação e a ideia de um processo frio (concreto) de estruturação, inclusive como fórmula de escrita de contos de mistério e policiais gêneros do qual Poe é considerado criador.

O corvo, no original The raven, foi publicado na França em 1875 pela editora Richard Lesclide, em uma edição limitada de 240 exemplares numerados e assinados por seu tradutor: Stéphane Mallarmé (com ilustrações de Édouard Manet). ${ }^{17}$ O poema é curiosamente transcrito em formato de $\operatorname{prosa}^{18}$. Poe é uma influência declarada para importantes poetas franceses como Mallarmé, Baudelaire e Valéry. ${ }^{19}$

\footnotetext{
17 Wikisource. Le Corbeau (Mallarmé). Disponível em:

https://en.m.wikisource.org/wiki/Le Corbeau (Mallarmé). Acesso em 15 feb. 2018.

18 O que revela um indicativo da busca de Mallarmé pela quebra métrica do poema em direção ao verso livre alcançado em Um lance de dados.

19 P. Mansell JONES, The Background of Modern French Poetry: Essays and Interviews By P. Mansell Jones (Cambridge: University Press, 1968. p 38)
} 
A combinação poema + explicação da composição do poema: a ênfase na cuidadosa escolha dos efeitos a se causar no leitor, a insistência no controle total do ato criativo, a resistência a deixar qualquer parte da construção entregue ao indiscernivel ou ao acaso. Se colocarmos Um lance de dados nessa equação, seria um passo adiante na conversa, o amálgama de poema e compreensão do poema e um possível argumento de que por mais que se decida e se registre, o controle é ilusório, ou temporário (imediato e devido à decisão). Mallarmé vai além e espacializa na página a decisão. "Os brancos com efeito assumem importância, agridem de início; a versificação os exigiu, como silêncio em volta." ${ }^{20} \mathrm{O}$ ato não exclui a fortuna, e se refeito, gera novas possibilidades. Entre as ruínas, sobre os escombros, as sombras e as sobras, existe a escolha - das páginas, dos pedaços, do que foi apagado, do que resta, do que deve restar - o que está revelado, o que é sugestão. ("O papel intervém cada vez que uma imagem, por si mesma, cessa ou retorna, aceitando a sucessão de outras" ${ }^{21}$ ). Não há romantismo ingênuo de criação espontânea ou inspiração improvisada/divina. Há o entendimento - ou ao menos a tentativa - do processo, o reconhecimento do objeto, do objeto como um todo, um completo - daí a importância para mim da revelação de Haroldo de Campos $^{22}$ da dimensão gráfica do poema. ("[A página] agora servindo de unidade [outra] do Verso ou linha"). Há o pensamento e o olhar do que, e sobre o que, está sendo criado durante o ato. Há o processo à mostra. Há a expectativa do que vai se gerar, o descontrole - imprevisto - sobre partes do processo ao se trazer estruturas vazadas, com falhas e aberturas. ("Terei, não obstante, indicado do Poema incluso, mais do que um esboço, um estado"). Há a observação: da perda e do ganho, dos possíveis que atravessam a página. Para tanto a compreensão, a criação consciente e alerta. Aberta. ("O suficiente para abrir os olhos"). Que aceita interrupções, desvios, feito a vida. Talvez por isso a importância para Edgard Braga de escrever o poema no poema, falar de escrita sendo escrita, pensar poesia no desenhar das letras.

20 Stéphane MALLARMÉ. Prefácio de Um lance de dados jamais abolirá o acaso.In.: CAMPOS 1974, p.151. 


\section{XIII}

Volto ao Lance de dados jamais abolirá o acaso. Acaso, no original em francês, hasard. Hasard: fortuna, sorte, acaso, possibilidade, imprevisibilidade ou, mais diretamente, azar (sem o teor negativo). Julia Kristeva, analisando a frase, escreve: "et imologicamente, porém, (árabe) ${ }^{23}$ hasard (o azar) quer dizer dado, de forma que a frase: Um lance de dados jamais abolirá o acaso constitui uma tautologia: 'um lance de dados jamais abolirá o (lance de) dado"' (KRISTEVA, 1972. p. 265). Gera-se assim um movimento circular autoreferente, do dado sobre o dado, do acaso sobre o acaso, da palavra sobre a palavra - não se enuncia um sujeito - o sujeito é o ato, quem escreve também é escrita.

\begin{abstract}
"Azar é também jogo (...) de onde sairá o número". Segundo Kristeva, o número representa para Mallarmé a ordenação, "a distribuição das diferenças a partir das quais se articulará o ato de significar". Número que não pode ser outro. O número surgido do acaso, do jogo, "a produção de números equivale, em Mallarmé, à produção textual, (...) ao qual o sujeito finito ordena o acaso infinito, o poema se torna uma construção raciocinada, uma arquitetura, um fenômeno regulável" (KRISTEVA, 1972. p. 264-265).
\end{abstract}

\section{XIV}

- Fomos para o gelo escorregadio onde não existe o atrito, e logo as condições são, em certo sentido, ideais, porém justamente por causa disso não podemos caminhar. Queremos caminhar: então precisamos do atrito. Voltemos ao solo áspero!(WITTGENSTEIN citado por AZEVEDO, 2017)

23 Hasard/azar tem origem etimológica no árabe sahr ou az-zahr, "que significa flor, em referência a figura de uma flor que era feita num tipo espécie de dado que os árabes usavam para jogar". Fonte: Dicionário Etimológico. Disponível em https://www.dicionarioetimologico.com.br/azar. Acesso em: 10 feb 2018. 
O dicionário aberto sobre a cadeira no canto da sala. Não sei se ele me entrega pouco ou se o uso demais (como perceber a diferença nas muletas nos ajudando a levantar e firmar e quando o apoio, cômodo, enfraquece nossos músculos?). Já terminei o que tinha para escrever. Mas o grosso volume Houaiss marrom com suas folhas sedosas deitadas, levemente translúcidas, a deslizar uma sobre a outra sobre a outra sobre a outra sobre a outra, me seduzem a espiá-lo novamente. Transmutação. A definição ainda lá, ato ou efeito de transmutar-se (transportar, transferir, mudar, converte em, tornar diferente). Desço mais dois degraus do verbete: 2 fís. nuc. qualquer reação nuclear que transforme um nuclídeo em outro 3 gen formação de uma nova espécie através do acumulo progressivo de mutações na espécie original. Não sei se o olhar mudou ou a ansiedade se acalmou, continuo: t. alquímica alq transformação de um metal sem valor em um metal precioso.

O que isso revela? Não é muito, quase nada, é quase um jogo, uma brincadeira. Um pouco mais, talvez. A compreensão de uma mudança mais profunda do que o olhar de Braga sobre a poesia - de assumir a metalinguagem - escrever e pensar a poesia na própria poesia. A partir do processo de observar o poema e depois manusear o poema. Feito um alquimista - testando elementos. Julia Kristeva, analisando o escrito "Ouro" de Mallarmé, escreve: "o ouro/ o tesouro é contraposto à moeda/ ao intercâmbio (à comunicação), a fim de que, finalmente, possa ser feita uma analogia: se as palavras são moedas (agentes da comunicação), o papel do poeta é transformálas em ouro - é devolver-lhes a pluralidade significante, a mais valia que a comunicação reduz, "em virtude da falta da moeda a brilhar abstratamente, produzse o dom, no escritor, de amontoar a claridade radiosa com palavras por ele proferidas"..."24 É a prática necessária para aprender um ofício, um pouco mais fundo para decifrá-lo. Pegar as palavras com a mão, sentir a espessura da tinta das palavras, a imprecisão das suas linhas. A mancha: tal qual uma explosão no laboratório: é preciso recomeçar - ou não: seguir daí pra diante: a mão suja, as letras sujas. Se sujar - Braga usou as mãos para garimpar, para executar o que identificou ao observar a estrutura do que entendia por poesia, executar a transformação de 
uma poesia dura em um experimento precioso. Cavar, cavar, cavar. Limpar tudo que é gesso, que endurece as articulações. Remover o verniz para deixar fluir. Voltar a andar. Com as mãos libera-se do peso formal do que deveria ser Poesia. Leve pra poder brincar (e deixar surgir outros problemas, acidentes, machucados). Braga faz uso dos gestos, do corpo, para cortar os excessos dos versos - remove as espumas de proteção da parede, do chão - e tocar, como um Midas, palavras e linhas, misturá-las, combiná-las, para além das próprias palavras. Gesto manual para trazêlas ao mundo.E percebe-se precisando de menos. Menos saudações, reverências, exibições - apenas as que queira. Condensação. Liquefação. Dissolução. Atravessar a esterilização tipográfica que pairava sobre suas letras, e se sujar (de tinta) como um açougueiro. A simples possibilidade do erro, do laboratório (a página) explodir pelos ares e ter que se reiniciar ou seguir daí. Dissolução: ato ou efeito de dissolver (entre outras coisas). 


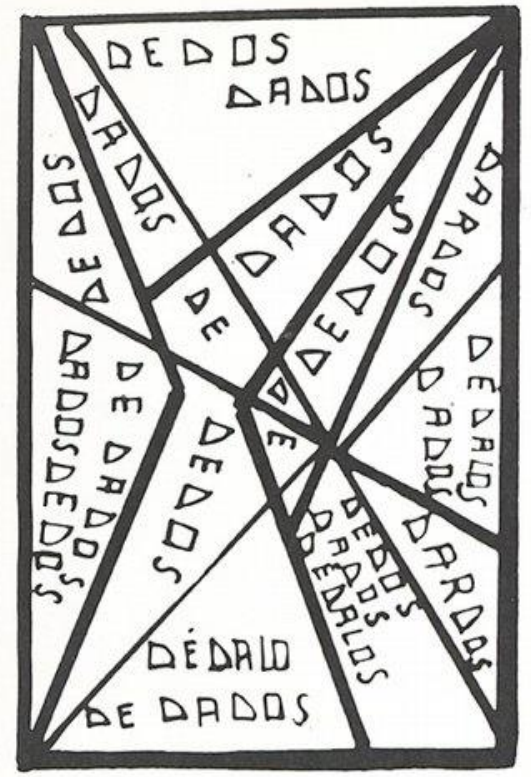

Poema de Edgard Braga, Dedos dados, feito em 1966 e publicado no livro Tatuagem (Edições Invenção, 1976).

Poema de Vasily Kamensky, Constantinopla, publicado no livro Tango with Cows (1914)

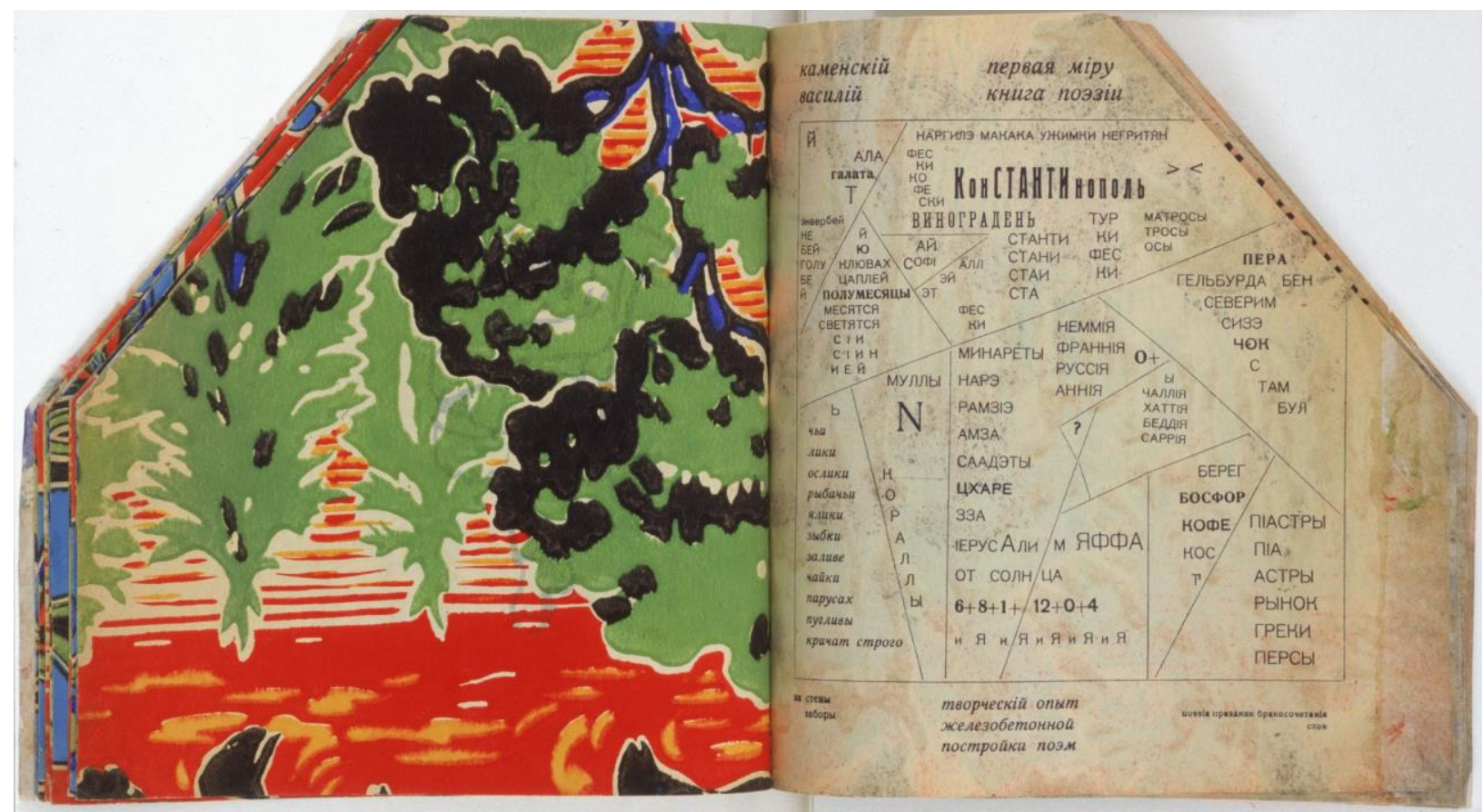

Eutomia, Recife, 22(1): 253-272, Dez. 2018 

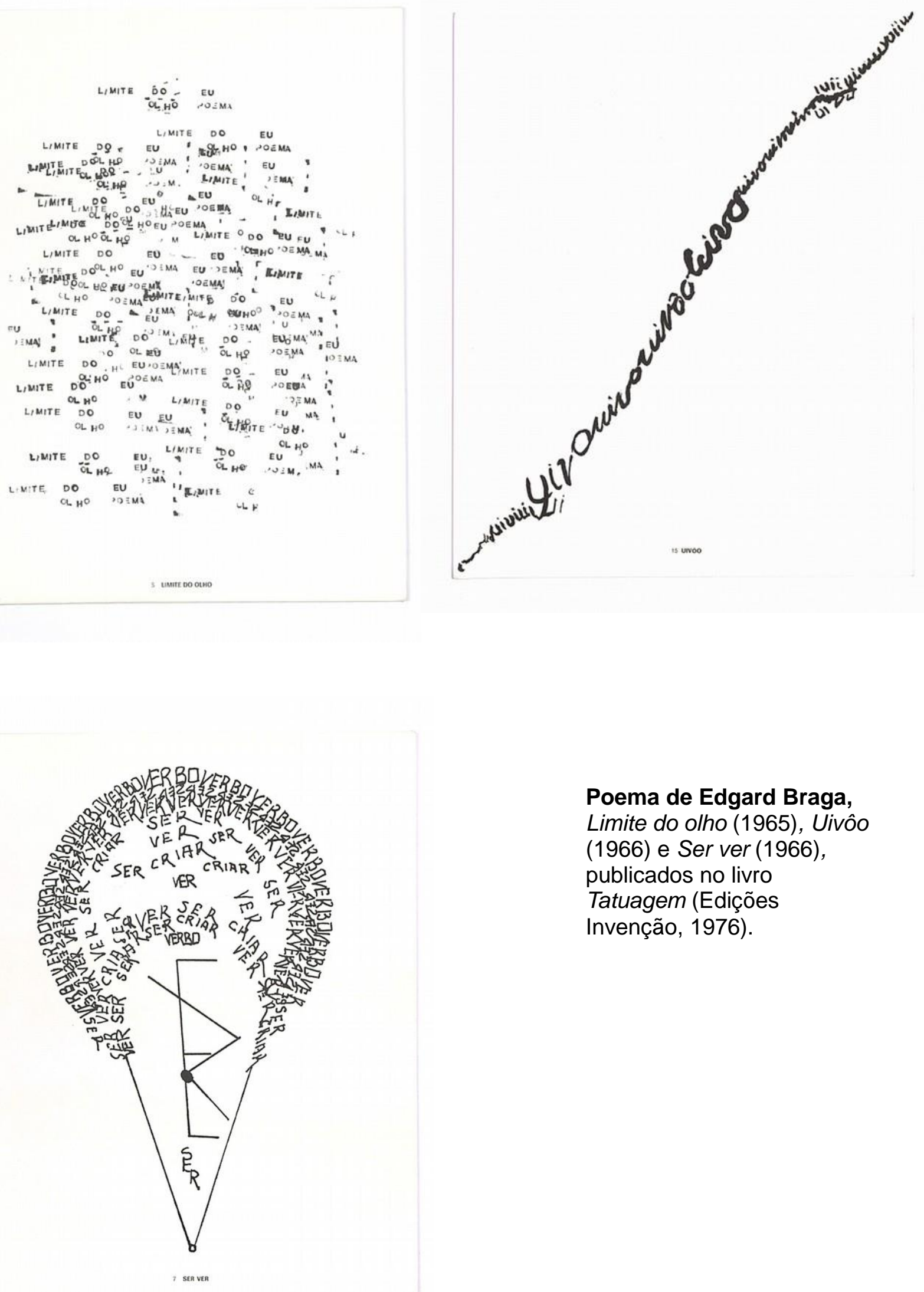

Poema de Edgard Braga, Limite do olho (1965), Uivôo (1966) e Ser ver (1966), publicados no livro Tatuagem (Edições Invenção, 1976). 


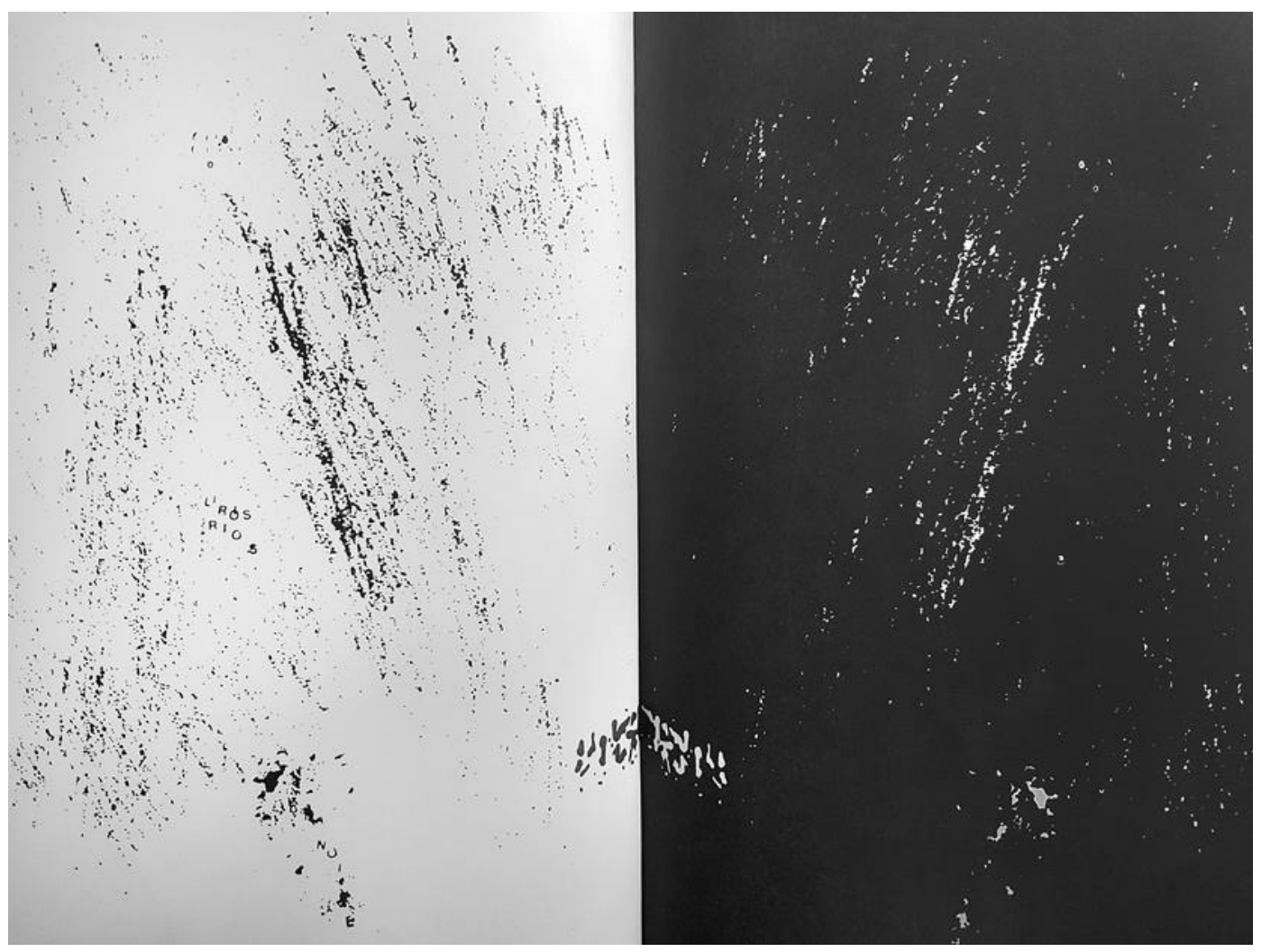

Foto das páginas do livro Algo (São Paulo, ed. Invenção, 1971), reproduzidas em Desbragada (1984), de Edgard Braga.

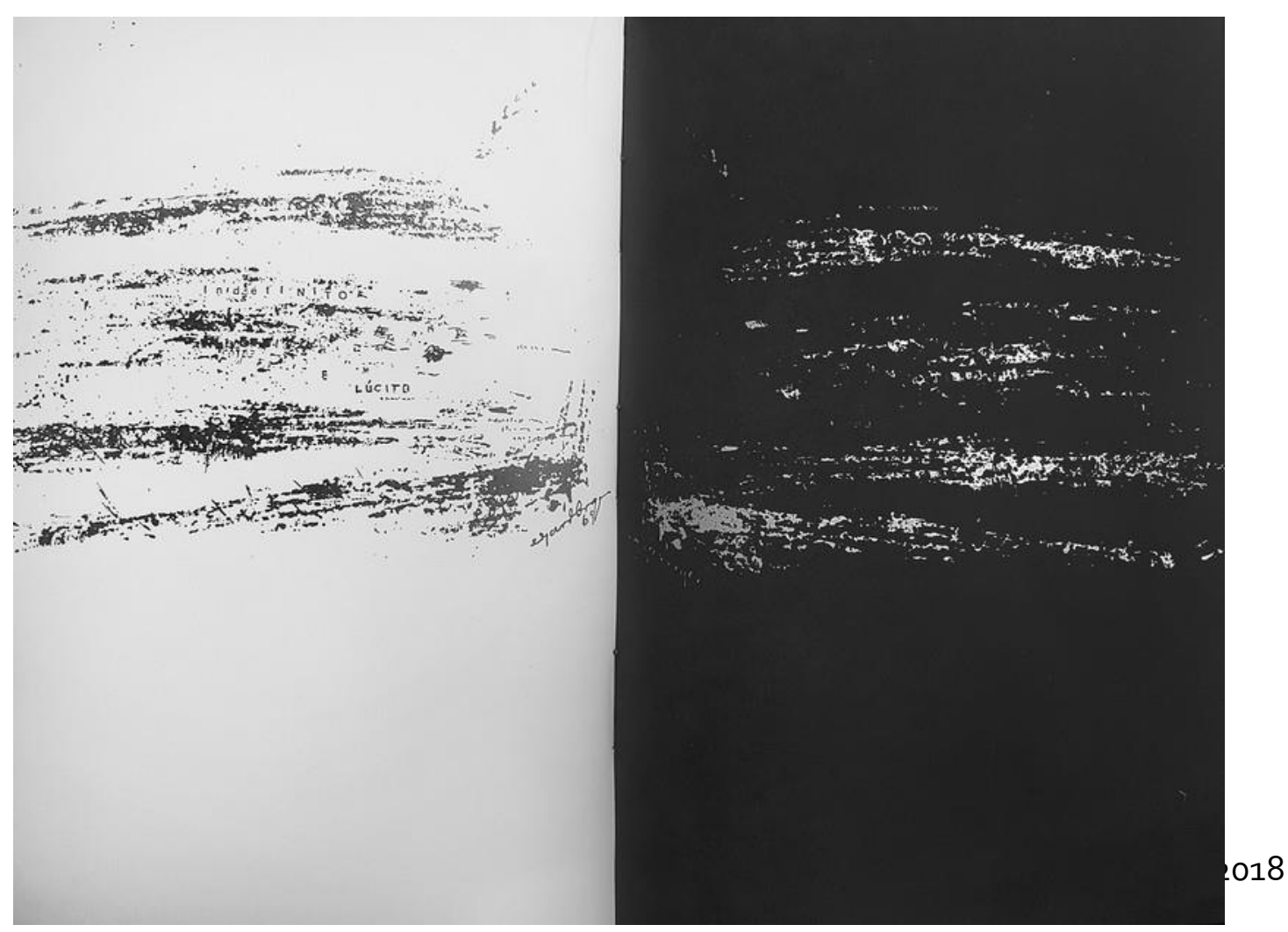




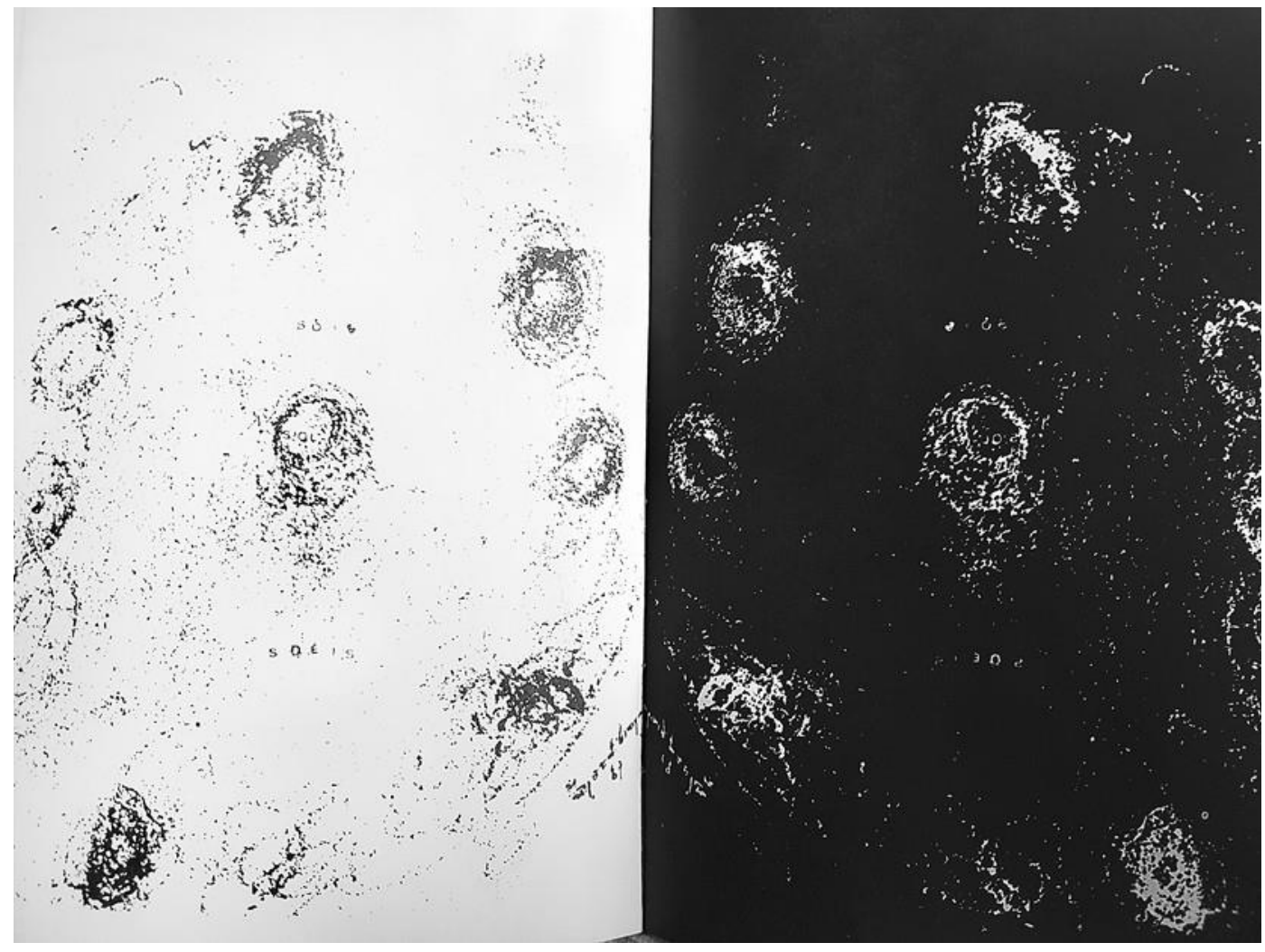

Foto das páginas do livro Algo (São Paulo, ed. Invenção, 1971), reproduzidas em Desbragada (1984), de Edgard Braga.

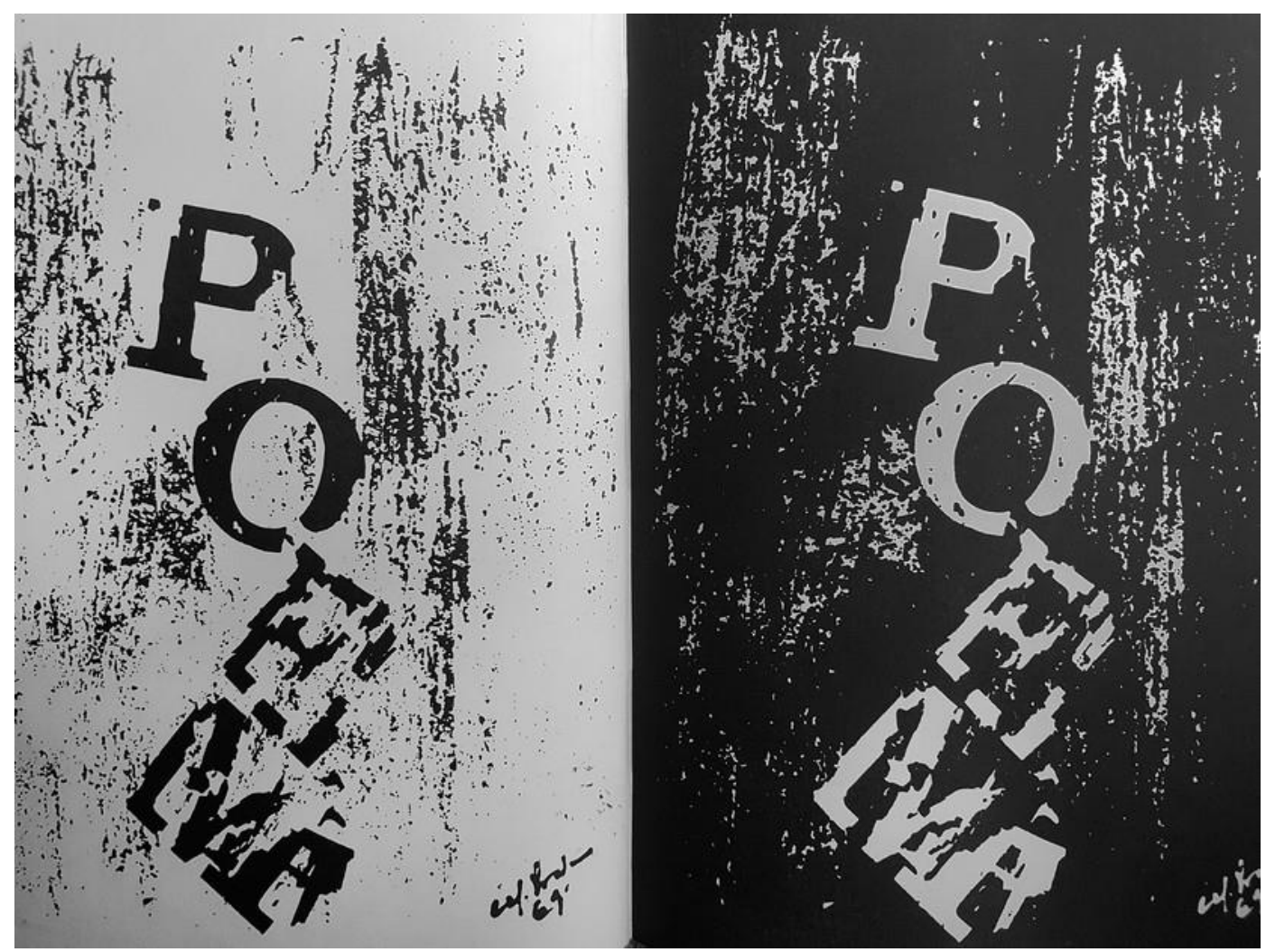

Eutomia, Recife, 22(1): 253-272, Dez. 2018 


\section{Referências bibliográficas}

AMARAL, Beatriz Helena Ramos. A Transmutação metalinguística na poética de Edgard Braga. São Paulo: Ateliê Editorial, 2013.

AZEVEDO, Flora Muniz Tucci de. Jogo de linguagem e a ética clínica ferencziana. 2017. Tese (Doutorado em Filosofia). PUC-Rio, Rio de Janeiro, 2017.

BANDEIRA, João (org.). BARROS, Lenora de (org.). Poesia concreta: o projeto verbivocovisual. São Paulo: Artemeios, 2008.

BRAGA, Edgard. Desbragada. São Paulo: Max Limonad,1984.

—. Tatuagens. São Paulo: Edições Invenção, 1976.

CAMPOS, Augusto; CAMPOS, Haroldo; PIGNATARI. Décio. Mallarmé. São Paulo: Perspectiva, Edusp, 1974 .

CAMPOS, Haroldo de. Ruptura dos gêneros na literatura latino-america. São Paulo: Perspectiva, 1977.

HOUAISS, Antônio. VILLAR, Mauro de Salles. Dicionário Houaiss da Língua Portuguesa. Rio de Janeiro: Objet iva, 2001.

JONES, P. Mansell. The background of modern french poetry: essays and interviews. Cambridge: University Press, 1968.

KRISTEVA, Julia. Semianálise e produção de sentido. Alguns problemas de semiót ica literária a proposto de um texto de Mallarmé: Un coup de dés. In: GREIMAS, A. J. (org.). Ensaios de semiótica poética. São Paulo: Cultrix, 1975. p. 238-268.

MALLARMÉ, Stéphane. Um lance de dados. São Paulo: Ateliê Editorial, 2017. 2a edição.

MENEZES, Philadelpho. A marca do criador: poesia caligráfica. In: WILLEMART, Philippe (org). Gênese e memória: anais do 40. encontro internacional do manuscrito e de edições. São Paulo: Annablume, 1995. p. 571-582.

POE, Edgar Allan. Medo clássico. Rio de Janeiro: Darkside Books, 2017. p. 349.

Omar Salomão (Rio de Janeiro, 1983): Doutorando no programa de Literatura, Cultura e Contemporaneidade pela PUC-Rio, é poeta, designer e artista plástico. 